\title{
How Can We Predict and Evaluate E-Learning Service Quality?
}

\author{
Mostafa Ahmed Shalash \\ PhD, Fellowship, MBA, Faculty of Financial \& Administrative Sciences, Pharos University, \\ Alexandria, Egypt
}

\begin{abstract}
The rapid development of internet has motivated the educational institutions to provide their services through this electronic channel. With technology revolution, the internet became a critical and an important channel for providing learning services. So, issue of e-learning quality became pivotal and all educational institutions must shift the focus from just providing e-learning to e-learning quality providing. It becomes obvious that providing e-learning quality is essential for surviving in the highly competitive learning environment. To evaluate any e-learning service quality provided by educational institutions, we need tools that can be used to measure e-learning service quality provided by such institutions. This paper will explore the use of multiple discriminant analysis in developing a model to alert educational institutions that provide poor elearning service quality. Results show that four variables (factors) are significant in the model development which is ease of use, security and privacy, reliability and responsiveness. So, the objectives of this article can be summarized as follows:

- developing a model to alert educational institutions that provide poor e-learning service quality (Q-Score Model);

- detecting which variables (factors) are the best predictors to discriminate between educational institutions that provide good e-learning services and institutions that are poor in providing such service;

- setting a cutoff point (cutoff value) to categorize the educational institutions according to the provided quality level of e-learning service (good or poor e-learning service quality).
\end{abstract}

\section{INTRODUCTION}

The recent development of information technology has led to major changes in the way services are delivered to the customers. Online services, including online learning are becoming an attractive alternative to visiting service outlets for increasing number of customers and consequently the profits. Some of the reasons for customers to prefer online services are convenience, feeling more control of the service process, avoiding human contact, and saving time [1,2]. In order to service providers retain their e-customers, they should have better understanding of how customers perceive and evaluate the quality of the electronically offered services. Although the literature on service quality is abundant [3], very little research has been conducted on the evaluation of the quality of services delivered over the internet [4].

The increased use of the internet in the future will increase the expectations and perceptions of customers, thus providing e-service quality is an increasingly important issue. Thus, understanding eservice quality issues within the new delivery channel becomes crucial.

Delivering high quality services is a prerequisite for achieving customer satisfaction and only through customer satisfaction can the service providers gain loyal customers [5].

From the mentioned above, it becomes obvious -for educational institutions- that the service quality is essential for surviving in the highly competitive e-service environment [6]. This leads to the fact, that a good understanding of the attributes that customers use to judge e-service quality is necessary in order to be able to monitor and enhance its performance and improves its overall e-service quality.

Several researchers have discussed the importance of e-service quality and have demonstrated its positive relationship with profits, increased market shares, return on investment, future purchase intentions and customer satisfaction [7, 8].

Now, an increasing number of educational institutions in Egypt offer facilities that allow students to study complete curriculum through the internet and receive their certificates after the completion of 
their studies. E-learning to compete effectively against traditional learning, service quality must be relatively higher. Among the challenges that face e-learning, identifying the dimensions that influence the e-learning service quality and how to measure this quality. Hiltunen et al. (2002)[9] argued that the key factor in e-learning competition is the quality of service provided by such institutions.

Recognizing that we can't manage what we can't measure, has emphasized the need to develop a valid and reliable model that identifies in advance which educational institute faces e-learning service quality problem. This is executed by calculating the discriminant score; This score is then will be compared with a cutoff value. If the score is below the cutoff value, the educational institute will be placed into group 2 (Provides poor e-learning service quality), otherwise it is placed into group 1 (Provides good e-learning service quality). Generally, the lower discriminant score, the poorer is the providing e-learning service quality. In addition, this model can be used to rank the educational institutions according to the value of discriminant score. The institute with higher discriminant score is better than the lower; it provides better e-learning service to his customers.

\section{Variables E-Learning Recipients use in Evaluating Perceived E-Learning QUALITY}

It was proved that there were nine dimensions of e-learning service quality should be taken into consideration when e-learning providers plan to introduce or improve e-learning service quality in educational institutions [10]. In this section, the nine dimensions will be mentioned briefly.

\subsection{Perceived Ease of Use}

Langeard et al [11] found that in deciding between alternatives of technology based self-service, customers considered the effort involved in using the e-service as an important factor. The researches suggested that potential customers of technology based self service are concerned about the effort required to use such service and the complexity of the process of that service. The two characteristics effort and complexity appear to be related and encompassed in "ease of use" found to be an important attribute to customers in using computer technology [12, 13, and 14)]. Rogers (1983)[15] defined perceived ease of use as it is the term that represents the degree to which the perceived innovation is not difficult to be understood, learn, or operate. He further stated that perceived ease of use is the degree to which consumers perceive a new product or service as better than its substitutes.

\subsection{Perceived usefulness}

According to Davis [12]; Ying [14], perceived usefulness is defined as the degree to which a user believes that using a particular system would enhance his or her job performance. Davis, in developing the Technology Acceptance model (TAM), proved that perceived usefulness is a significant factor effects the acceptance of any new technology [12, 16]. Tan and Teo (2000) [17] suggested that the perceived usefulness is an important factor in determining adoption of innovations. As a consequence, the greater the perceived usefulness of using electronic services, the more likely that electronic services will be adopted $[18,19]$.

\subsection{Perceived Security and Privacy}

Security and Privacy are key evaluative criteria in online services [20, 21]. These two related criteria have been distinguished from each other. Security involves protecting users from the risk of fraud and financial loss from the use of their credit card or other financial information. Privacy, on the other hand, involves the protection of personal information, not sharing personal information collected about consumers with other sites and providing informed consent [22, 23]. Generally, security and privacy have been shown to have a strong impact on attitude toward use of online services [21].

\subsection{Perceived Variety of Services Offered}

Providing ranges of electronic services that satisfy all customer needs is an important component of automated service $[24,25]$. The diversification in services provided represent a set of elements that could positively impact on automated service satisfaction levels [26] and have a significant effect on the success of automated delivery channels [27]. Therefore customer perceptions of the variety of services offered by e-learning providers will be considered as another predominant factor that could influence overall customer perception of automated learning service quality.

\subsection{Perceived Reliability}

Reliability is defined as the ability to perform the promised service dependably, on time, and accurately [28]. In another research [29], reliability dimension has been found to be the most 
significant predictor of customer satisfaction. Parasuraman et al. [28] referred to reliability dimension as an important determinant of service quality. In a survey of service quality [30, 31], it was found that reliability was the most important factor in determining service quality.

\subsection{Perceived Responsiveness}

This dimension includes quick response and the ability to get help if there is a problem or question related to the e-service offered. Parasuraman et al.[32] proved that this dimension is significant and highly correlated with e-service quality. Therefore, responsiveness will be considered as another predominant factor that could influence overall perceived e-learning service quality.

\subsection{Perceived Convenience}

Over a decade, large market surveys [33, 34, 35, and 36] have reported that one of the main factors driving people to online services is convenience. Based on a survey of 1355 respondents [37], it was discovered that current and prospective adopters perceived convenience as a determinant of intention to adopt e-services. Convenience in e-learning refers to the capability to access e-courses at anytime and anywhere.

\subsection{Perceived Compensation}

It is the degree to which the site compensates e-learning recipients for problems or mistakes occurred by the site. Parasuraman et al.[32] proved that this dimension is significant and highly correlated with e-service quality. Therefore, compensation will be considered as another predominant factor that could influence overall perceived e-learning service quality.

\subsection{Perceived Efficiency}

This dimension introduced by Parasuraman et al., [32]. The efficiency dimension refers to the ability of the customers to get to website, search for information and logout with minimal effort. The effect of this dimension in overall perceived e-service quality was verified and the result was significant. Also, the study that was conducted by Parasuraman et al.[32] showed this dimension is highly correlated with e-service quality. Yet, the findings from the mentioned study explained that the efficiency dimension is the most critical one in e-service quality and has strongest influence not only on overall quality perceptions but also on loyalty intention.

\section{ENSURING THE VALIDITY}

Validity is the extent to which the questionnaire accurately measures what it is supposed to measure [38]. Eriksson and Wiederscheim [39] defined the validity as: "the ability of a scale or instrument to measure what is intended to be measured". In this research, the Expertise validity has been applied to ensure the validity of questionnaire. The pilot study was conducted with the reviewed version of the questionnaire among fifteen of different e-learning service recipients, who ensured that the questionnaire is appropriate and the statements are generally understandable. Based on this information, the questionnaire is finalized.

\section{ENSURING THE RELIABILITY}

Reliability is the internal consistency of the questionnaire. In other words, it is the extent to which the questionnaire yields the same results on repeated trials under the same conditions [38]. The questionnaire is considered reliable when the same or similar scores are obtained in repeated testing with the same group of respondents [40]. In this research, Cronbach's alpha coefficient for internal consistency technique is used to ensure the reliability of questionnaire [41, 42]. The results of Cronbach's alpha are depicted in table1

Table1. Reliability Test

\begin{tabular}{|l|l|}
\hline Cronbach's alpha coefficient & N of items \\
\hline .926 & 40 \\
\hline
\end{tabular}

Cronbach's alpha reliability coefficient normally ranges between 0 and 1 . The closer Cronbach's alpha coefficient is to 1.0, the greater the internal consistency of the items in the scale [42]. Values of 0.7 and above are usually considered adequate values of coefficient alpha [41], while Gliem [42] mentioned that the alpha reliability coefficient of .8 is a reasonable goal. In our study, Cronbach's alpha reliability coefficient $=.926$ which means this questionnaire is highly reliable. 


\section{THE RESEARCH SAMPLE}

After ensuring the validity and reliability of the questionnaire, the researcher starts Stage two which involved distribution of twenty surveys to a random sample of e-learning recipients. The researcher determined the estimated sample size by using the statistical application program Epi Info. Respondent was asked to show the extent to which he or she believes his/her education or training institution has the feature described by statement on a five point Likert scale ranging from lindicating strongly disagree to 5 indicating strongly agree.

\section{Multiple Discriminant Analysis}

Discriminant analysis is a statistical technique used to classify the dependent variable into two or more categories. It has a regression technique [43], which is used for predicting the value of the dependent variable. Another objective for this technique, it allows the professionals to place the dependent variable, overall online learning service quality in our case, into one of two groups depending on a calculated score "discriminant score". This score is then compared to a cutoff value. If the score is below the cutoff value, the dependent variable will be placed into group 2 (provides poor online learning service quality), otherwise, it is placed into group1 (provides good online learning service quality). Generally, the lower discriminant score, the poorer is the providing online learning service quality.

In addition, this model can be used to rank the educational institutions according to the value of discriminant score. The institution with higher discriminant score is better than the lower; it provides better online service to his customers.

In the following subsections, the proposed model (Q-Score model) that can be used to evaluate and predict the quality level of provided e-learning services, will be presented.

\section{RESULTS AND INTERPRETATION}

The results of the multiple discriminant analysis are depicted in tables 2

Table2. Classifying e-learning educational institutions

\begin{tabular}{|l|l|}
\hline overall perceived quality category & Cases \\
\hline 1 good & 12 \\
\hline 2 poor & 8 \\
\hline Total & 20 \\
\hline
\end{tabular}

Table3. Variables in the Analysis

\begin{tabular}{|l|l|l|l|}
\hline Variables & Tolerance & F to Remove & Wilks' Lambda \\
\hline Dimension 1 Ease of use & .668 & 14.083 & .032 \\
\hline Dimension 3 security \& privacy & .410 & 28.240 & .048 \\
\hline Dimension 5 reliability & .529 & 26.681 & .046 \\
\hline Dimension 9 efficiency & .545 & 8.523 & .026 \\
\hline
\end{tabular}

Results drawn from tables 2 and 3 are summarized and explained below.

- The dependent variable (overall perceived e-learning service quality) is a categorical variable that consists of 1 and 2 . If e-learning service under quality performing, it will be categorized into 2 . On the other hand, the educational education will be categorized into 1 if it provides good e-learning service quality. This categorical procedure is built on an assumption which is: the overall perceived e-learning service should equal to or greater than $65 \%$ to be considered good online service quality, otherwise, it will be poor e-learning service quality.

- Discriminant analysis nominated four variables, X1 ease of use, X3 security \& privacy, X5 reliability, and X9 efficiency that are considered predictor variables which contribute in classifying the dependent variable (the overall perceived e-learning service quality). In other words, these variables are the best predictor variables that can be used to predict the dependent variable in which group can be placed into.

Table4. Summary of Canonical Discriminant Functions

\begin{tabular}{|c|c|c|c|c|}
\hline Function & Eigenvalue & \% of Variance & Cumulative \% & Canonical Correlation \\
\hline 1 & 58.883 & 100.0 & 100.0 & .992 \\
\hline
\end{tabular}


How Can We Predict and Evaluate E-Learning Service Quality?

Table5. Wilks' Lambda

\begin{tabular}{|c|c|c|c|c|}
\hline Test of Function(s) & Wilks' Lambda & Chi-square & df & Sig. \\
\hline 1 & .017 & 65.478 & 4 & .000 \\
\hline
\end{tabular}

- Tables 4 and 5 depict that the discriminant function has a wilks' lambda value .017 . Lambda has a value between $0 \& 1$. The value 0 indicates major difference between the groups and the value 1 means no difference [43]. The lambda value .017 means that the discriminant function has a great ability to distinguish the groups. This result is confirmed in the output analysis which shows both of the groups can be discriminated significantly, in other words, discriminant function is significant.

- The square root of canonical correlation is .996 . It means $99.6 \%$ of the variability of the dependent variable (overall perceived e-learning service quality) can be explained with this discriminant function. [43].

- Using the four variables that have been candidate by the previous analysis, $\mathrm{X} 1, \mathrm{X} 3$, X5, and X9, we can form the discriminant function for e-learning educational institutions as follows.

$\mathrm{Q}=\mathrm{C}+\mathrm{b} 1$ ease of use $+\mathrm{b} 3$ security \& privacy $+\mathrm{b} 5$ reliability $+\mathrm{b} 9$ efficiency

$\mathrm{Q}=\mathrm{C}+\mathrm{b}_{1} \mathrm{X}_{1}+\mathrm{b}_{3} \mathrm{X}_{3}+\mathrm{b}_{5} \mathrm{X}_{5}+\mathrm{b}_{9} \mathrm{X}_{9}$

Where:

$\mathrm{Q}$ is the discriminant score;

$\mathrm{C}$ is a constant;

b1 is the discriminant coefficient for ease of use dimension;

$\mathrm{X} 1$ is the value of perceived ease of use,

b3 is the discriminant coefficient for security \& privacy dimension;

$\mathrm{X} 3$ is the value of perceived security \& privacy;

b5 is the discriminant coefficient for reliability dimension;

$\mathrm{X} 5$ is the value of perceived reliability;

b9 is the discriminant coefficient for efficiency dimension;

X9 is the value of perceived efficiency.

Table6. Discriminant Function Coefficients

\begin{tabular}{|l|c|}
\hline & Function Coefficients \\
\hline Dimension 1 Ease of use & .160 \\
\hline Dimension 3 security \& privacy & .243 \\
\hline Dimension 5 reliability & .183 \\
\hline Dimension 9 efficiency & .155 \\
\hline Constant & -23.480 \\
\hline
\end{tabular}

Using results that has been depicted in table 6 , we can reform the discriminant function in the following model

$\mathrm{Q}=-23.48+.16 \mathrm{X}_{1}+.243 \mathrm{X}_{3}+.183 \mathrm{X}_{5}+.155 \mathrm{X}_{9}$

Table7. Standardized Discriminant Function Coefficients

\begin{tabular}{|l|c|}
\hline \multicolumn{1}{|c|}{ Dimension } & Function \\
\hline Dimension 1 Ease of use & .858 \\
\hline Dimension 3 security \& privacy & 1.272 \\
\hline Dimension 5 reliability & 1.110 \\
\hline Dimension 9 efficiency & .823 \\
\hline
\end{tabular}

Standardized discriminant coefficients are used to compare the relative importance of the independent variables. Table 7 depicts that the Dimension 3; security \& privacy has a big influence in the discriminant model; it has a high relative importance in building this model, in other words, it has the highest contribution ratio in classifying the dependent variable (the overall perceived e-learning 
service quality). Standardized discriminant coefficient for this variable is 1.272 , followed by dimension 5; reliability 1.11 , then dimension 1 ; ease of use .858 , and the last is dimension 9; efficiency .823

\section{Assessing the Cutoff Point}

Table8. Functions at Group Centroids

\begin{tabular}{|l|l|}
\hline overall perceived quality category & Function \\
\hline 1 good & 5.944 \\
\hline 2 poor & -8.916 \\
\hline
\end{tabular}

From centroied data (table 8), we can calculate the cut off point that is divide the discriminant score between group 1 (good e-learning service quality) and group 2 (poor e-learrning service quality). The cut off point is calculated as follows.

$\mathrm{Qcu}=\frac{\mathrm{N}_{1} \mathrm{Z}_{1}+\mathrm{N}_{2} \mathrm{Z}_{2}}{\mathrm{~N}_{1}+\mathrm{N}_{2}}$

Where:

Qcu : the quality cutoff point;

$\mathrm{N}_{1}$ : Number of samples in group 1 "good";

$\mathrm{N}_{2}$ : Number of samples in group 2 "poor";

$\mathrm{Z}_{1}$ : Value of centroid for group 1 ;

$\mathrm{Z}_{2}$ : Value of centroid for group 2.

$\mathrm{Qcu}=$ $\frac{12 * 5.944+8 *-8.916}{20}$

$\mathrm{Qcu}=$

- The cutoff point is 0.0. This means, the educational institutions that provide e-learning service with discriminant score (Q score) less than 0 (negative) will be grouped as poor in providing e-learning service quality and the educational institutions that provide e-learning service with discriminant score (Q score) higher than 0 (positive) will be grouped as good in providing e-learning service quality.

Table9. Classification Results

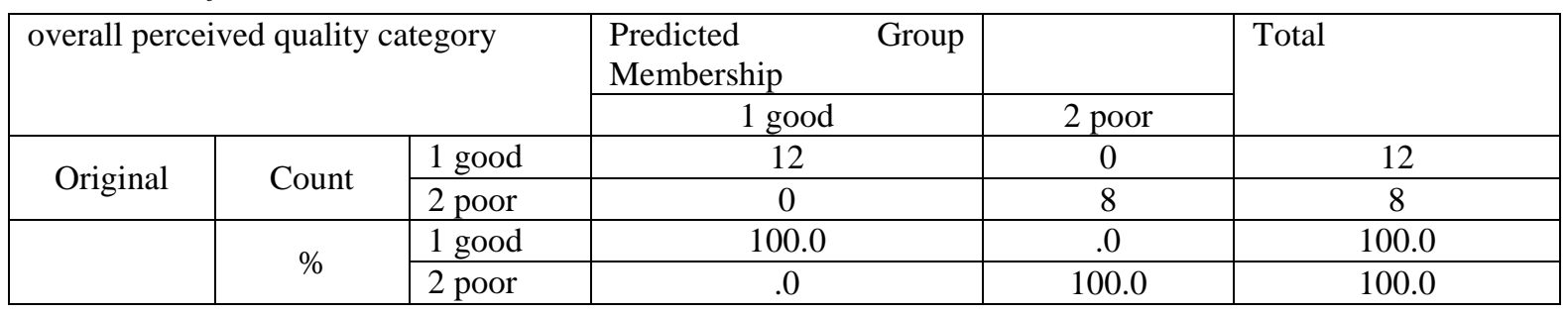

$100.0 \%$ of original grouped cases correctly classified

Table 9 depicts that the discriminant function "discriminant model" has an accuracy rate of $100 \%$ (hit ratio); the function precisely classifies the dependent variable into two categories. In other words, $100 \%$ of the grouped cases are correctly classified. This accuracy can be obtained only if the respondents avoid the neutral selection in the likert scale. The hit ratio is an individual percentage that measures the accuracy of discriminant function to predict the object of the group [43].

\section{CONCLUSIONS AND STRATEGIC IMPLICATIONS}

The goals of this study were:

- developing a model to alert educational institutions that provide poor e-learning service quality;

- detecting which variables (factors) are the best predictors to discriminate between educational institutions that provide good e-learning services and institutions that are poor in providing such service; 
- calculating a cutoff point (cutoff value) to categorize the educational institutions according to the quality level of e-learning service (good or poor e-learning service quality).

The findings of this study have important implications for research and educational institutions that are currently offering such online services as well as educational institutions that are planning to offer such services. This study provides further evidence on the relative importance of the predictor variables in classifying the dependent variable. In other words, measures the contribution of each independent variable to the explanation of the variation of the dependent variable.

- The predictor variables which contribute in classifying the dependent variable (the overall perceived e-learning service quality) in educational institutions that provide e-learning service are: (ease of use, security \& privacy, reliability, and efficiency). In other words, these variables are the best predictors that can be used to predict the dependent variable in which group can be placed into (good e-learning service quality or poor online service quality).

- The discriminant function has a wilks' lambda value .017 , which means the discriminant function has a great ability to distinguish the groups; it can accurately put the e-learning institution in its suitable group (good or poor) according to the provided quality level of e-learning services.

- The square root of canonical correlation is .996 which means, $99.6 \%$ of the variability of the dependent variable can be explained by this discriminant function. [43].

- Standardized discriminant coefficients are used to show the contribution of each variable in discriminant function to discriminate between which educational institute provides good online services and which one is poor in providing such service. It was explained that the security \& privacy dimension has the highest contribution in the discriminant function; it has a high relative importance in building this model, standardized discriminant coefficients for this variable is 1.272, followed by reliability dimension 1.11 , then ease of use dimension .858 , and the last dimension is efficiency .823

- The cut off point is 0.0 . This means, the e-learning institution with discriminant score less than 0 (negative) will be grouped as poor in providing e-learning service quality and the e-learning institution with discriminant score higher than 0 (positive) will be grouped as good in providing elearning service quality.

- The discriminant function "discriminant model" has an accuracy rate of $100 \%$ (hit ratio); the function can precisely classify the dependent variable into two categories. In other words, $100.0 \%$ of the grouped cases are correctly classified.

\section{Contributions of The Study}

The Contributions of this study can be divided into three sections as follows.

\subsection{Theoretical Contributions}

Taking into consideration the huge investments e-learning institutions make in internet infrastructure, customer satisfaction of online learning and retention are crucial factors for success in this field. One of the ways for achieving high customer satisfaction and gaining the loyalty of e-learning customers is offering high quality online services. That is why measuring and evaluating the quality of e-learning service is deemed important for educational institutions to be able to take actions to correct those features of their online services which customers don't find that satisfactory. From a theoretical point of view, the study presented contributions to the existing literature in a number of ways that are listed below.

- The study makes a contribution to e-learning literature by providing insights on the factors that seem to affect e-learning acceptance. It outlines the main dimensions that can be used to predict the level of e-learning service quality in educational institutions.

- Despite the growing role of technology in service delivery, the studies on self-service technology in general and education service in particular are needed. In addition, there are limited researches has been conducted on the issue of service quality in the context of self-service technology [1, 44]. Therefore, the present study attempts to fill this theoretical gap

- There are many studies identifying the key service quality factors in the traditional service environment, where the interaction between service provider and service recipient is the main 
communication channel [45,46]. However, Researches on automated service are still in its infancy phase and there is no generally accepted theoretical conceptualization of e-learning service quality.

- Extensive researches on traditional service quality have been conducted during the past 20 years. In contrast, only a limited number of researches deal with how customers assess e-service quality [32]. So, this study attempts to fill the gap in this side.

\subsection{Managerial Contributions}

- The study includes implications for managers of educational institutions showing how they can classify their institutions into one of two groups depending on a calculated score "discriminant score". If the score is below the cutoff value, the educational institution will be placed into group 2 (provides poor e-learning service quality), otherwise, it is placed into group 1 (provides good elearning service quality).

- Rank the e-learning institutions according to the value of discriminant score. The institution with higher discriminant score is better than the lower; it provides better e-learning service to his customers.

- E-learning have largely expanded, which paved the way to self-service channels. So, it is important to provide a study to correspond this conversion in the way of providing these services.

\subsection{Academic Contributions}

- Developing a quality prediction model for educational institutions that provide e-learning services (Q-Score model) to help professionals to identify in advance which institute may face online service quality problem.

- Calculate the discriminant function value "discromonant score" which can be compared with the cutoff value to predict in which group can the e-learning institute be placed into. If the score is below the cutoff point, the institute will be placed into group 2 (provides poor e-learning service quality), otherwise, it is placed into group1 (provides good e-learning service quality.

- Set a cutoff value to classify the educational institutions, either provide high quality online service to his customers or not.

- Detect which variables are the best predictors to discriminate between educational institutions that provide good online services and those that poor in providing such service.

- Assess the relative importance of the predictor variables in classifying the dependent variable. In other words, measures the contribution of each independent variable to the explanation of the variation of the dependent variable.

- Till now, there is no a reasonable instrument can be accepted from all academics and practitioners to be used as a standard measure to predict in advance which educational institution may provide good or poor e-learning service quality. Therefore, the findings of this study have a considerable value to the academic community in that it contributes to the growing understanding of learning perceptions for learning services carried over the internet.

- There are few studies that have manipulated the automated service quality in educational institutions. As a result, there is a need for further empirical investigation into the most pertinent factors to be used to discriminate between different educational institutions in the point of providing e-learning service quality to their customers.

\section{FUTURE RESEARCH}

- Four variables; ease of use, security \& privacy, reliability, and efficiency that are considered predictor variables which contribute in classifying the dependent variable (the overall perceived elearning service quality). In other words, these variables are the best predictor variables that can be used to predict the dependent variable in which group can be placed into (good or poor e-learning service quality). Furthermore, forty items were used to describe these four dimensions. Researchers might search about additional dimensions or additional items to be taken in the consideration to precisely judge the perceived e-learning service quality.

- A further study can be conducted to find the linkage between quality dimensions of e-learning service and satisfaction of e-learning recipients. 
- The number of items used in the model to describe each quality dimension is limited. Further researches should include more elaborated and detailed items to describe each dimension objectively.

- The researcher strongly recommends the researchers to conduct separated studies using the discriminant score and cutoff point to rank the educational institutions according to the quality level of online services provided.

\section{REFERENCES}

[1] Bitner, M., and Meuter, M. (2000). Technology infusion in service encounters", Journal of the academy of marketing science, Vol. 28, pp. 138-149.

[2] Dabholkar, P. and Rentz, J. (1996). A Measure of Service Quality for Retail Stores: Scale Development and Validation, Journal of the Academy of Marketing Science, Vol. 24, pp. 3-16

[3] Zeithaml, A., Parasuraman, A., and Berry, L. (1996). The behavioral consequences of service quality, Journal of Marketing, Vol. 60, pp. 31-46

[4] Cox, J. and Dale, B. (2001). Service quality and e-commerce: an exploratory analysis, Managing service quality, Vol. 3, No. 2, pp. 121-131.

[5] Gronroos, C. (2000). A service quality model and its marketing implication, European Journal of Marketing, Vol.18, pp. 35-44

[6] Wang, Y., Lo, H., \& Hui, Y. (2003). The Antecedents of Service Quality and Product Quality and Their Influences on Bank Reputation: Evidence from the Banking Industry in China, Managing Service Quality, Vol.13, pp72-83.

[7] Anderson, E.,Fornell, C., and Lehmann, D.(1994). Customer satisfaction, market share, and profitability: findings from Sweden, Journal of Marketing, Vol. 58, July, pp. 53-66.

[8] Fornell, C., Roland, T., and Marnik, G. (2010). The effect of customer satisfaction on consumer spending growth, Journal of marketing research, pp. 28-35

[9] Hiltunen M., Laukka M., Luomala, J. (2002). Mobile User Experience, IT Press, Finland.

[10] Shalash, M. (2012). E-Learning Qual: The way for ensuring e-learning service quality, ICT In Our Lives conference, Faculty of Commerce, Alexandria, Egypt.

[11] Langeard, E., Bateson, G., Lovelock, H, and Eiglier, P. (1981). Marketing of services: New insights from consumers and managers, Report No. 81-104, Marketing Science Institute, Cambridge.

[12] Davis, D. (1989). Perceived usefulness, perceived ease of use, and user acceptance of information technology, MIS quarterly.

[13] Bagozzi, R.(1990). Buyer behavior models for technological products and services: A critique and proposal, Advances in telecommunications management, Vol. 2, pp. 43-69

[14] Ying, W., Chun, L., Oscar, L., and Hsing, H. (2010). A Study of bank customers perceived usefulness of adopting online banking, Global journal of business research, Vol. 4, pp. 101-108

[15] Rogers, E. (1983). Diffusion of innovations, $4^{\text {th }}$ ed., the free press, New York.

[16] Yung, C., Chiang, C., and Ming, T. (2011). Using the technology acceptance model to analyze ease of use of a mobile communication system, Social behavior and personality, Vol. 39, pp. 6570

[17] Tan, M., Teo, T. (2000), Factors influencing the adoption of internet banking, journal of the association for information systems, Vol. 1, No. 5, pp.22-38

[18] Polatoglu, V., and Ekin, S. (2001). An empirical investigation of the Turkish consumers' acceptance of internet banking services, international journal of bank marketing, Vol.19, No.,4, pp. 156-165.

[19] Jaruwachirathanakul, B., and Fink, D. (2005). Internet services adoption strategies for a developing country: the case of Thailand, International Journal of Marketing Vol.15, No.3, pp. 295-311.

[20] Culnan, J. (1999). Georgetown Internet Privacy Policy Survey: Report to the Federal Trade Commission", Retrieved from http://www.gsb.georgetown.edu/faculty/culnanm/GIPPS/mmrp t.PDF

[21] Montoya, M., Voss, B., and Grewal, D. (2000). Bricks to clicks: What drives customer use of the internet in a multi channel environment, Working paper, Caroline State University. 
[22] Friedman, B. (2000). Kahn, H., and Howe, C., Trust online, Communications of the ACM, Vol. 43, pp. 34-40.

[23] Khalaf, A., and Ali, H. (2011). E-banking functionality and outcomes of customer satisfaction: An empirical investigation, International journal of marketing studies, Vol. 3, Issue 1

[24] Riel, A., Liljander, V. and Jurriens, P. (2001), Exploring consumer evaluations of E-Services: A portal site, International Journal of Service Industry Management. Vol.12, No.4, pp. 359-377.

[25] Yu, C., and Fen, Y. (2007).Factors Encouraging people to adopt online banking services, retrieved from: http://ibacnet.org/bai2007/proceedings/Papers/2007bai7075.pdf

[26] Szymanski, D., and Hise, R. (2000). E-Satisfaction: An initial examination, Journal of Retailing, Vol.76, No.3, pp. 309-322.

[27] Hway, O. and Yu, C. (2003). Success factors in e-channels: The Malaysian scenario, International Journal of Marketing, Vol.21, No.6, pp. 369-377.

[28] Parasuraman, A., Zeithaml, V., and Berry, L. (1988). SERVQUAL: A multiple item scale for measuring consumer perceptions of service quality, Journal of Retailing, Vol. 64, No.1, pp. 1240.

[29] Yee,M., Siu, N., and Jeremy C. (2005). Measuring service quality in Internet banking: The case of Hong Kong, Journal of International Consumer Marketing, Vol. 17, pp. 99-116.

[30] Gorder, B. (1990), Satisfying the customer of the 90's, The credit, Vol., 16, pp. 10-15

[31] Perm, S. (2008). Antecedents consequences of service quality in consumer evaluation of selfservice internet technologies, Service industries journal, Vol. 28, pp.117-138

[32] Parasuraman, A., Zeithaml, V., Malhorta, A., (2005). E-S-QUAL: a multiple-item scale for assessing electronic service quality, Journal of Retailing, Vol. 64, pp.12-40.

[33] Howcroft, B., Hamilton, R, and Hewer, P. (2002). Consumer attitude and the usage and adoption of home-based banking in the United Kingdom, the international journal of banking marketing, Vol. 20, No. 3, pp. 111-121.

[34] Laforet, S., and Li, X. (2005). Consumers' attitude towards online and mobile banking in China, International journal of bank marketing, Vol. 23, No. 5, pp. 362-380.

[35] Freed, L. (2005). Online banking charging into the future, Michigan Banker,Vol.17, No.6, pp. 98-99.

[36] Shabbir, M., Kaleen, A., and Kirmani, S. (2011). Customers' perceptions towards adoption of eservice on Pakistan, International journal of economics and business research, Vol.3, pp.1-14.

[37] Lee, E., Kwon, K., \& Schumann, D. (2005). Segmenting the non-adopter category in the diffusion of Internet banking, International Journal of Bank Marketing, Vol. 23, No. 5, pp. 414437.

[38] Carmines, G., and Zeller, A. (1979). Reliability and validity assessment, Sage publications. Inc.

[39] Eriksson, L., \& Wiederscheim, F. (1997). Att Utreda, Forska och Rapportera. Malmö: Liber Ekonomi.

[40] Miller, J.( 2005). Reliability and Validity- Graduate research methods, Western International University

[41] Nunnally, J. and Bernstein, H. (1994). Psychometric theory, $3^{\text {rd }}$ ed., New York: McGraw-Hill.

[42] Gliem, A and Gliem, R. (2003). Calculating, Interpreting, and Reporting Cronbach's Alpha reliability coefficient for Likert-type scales, Midwest research to practice conference in adult, continuing, and community education, pp. 82-88.

[43] Kertapati, et al.,(2004) Evaluating Company's Performances Using Multiple Discriminant Analysis, presented at UIBMC conference

[44] Selvan, N. and Arasu, B. (2011). Role of existing channels on customer adoption of new channels: A case of ATM and internet banking, The electronic journal of information systems in developing countries, Vol. 45, pp. 1-15

[45] Jun, M. and Cai, S. (2001). The key determinants of internet services quality: A content analysis, International Journal of Marketing, Vol. 19, No.7, pp. 276-291.

[46] Barbara, C. and Rojsek, I. (2010). Identifying service quality dimensions as antecedents to customer satisfaction, Economic and business review, Vol. 12, No. 3 